\title{
Parameter Optimisation of Power Regeneration on the Hydraulic Electric Regenerative Shock Absorber System
}

\author{
Peng Zheng $\left(\mathbb{D},{ }^{1}\right.$ Ruichen Wang $\left(\mathbb{D},{ }^{2}\right.$ Jingwei Gao, ${ }^{1}$ and Xiang Zhang ${ }^{3}$ \\ ${ }^{1}$ College of Aerospace Science and Engineering, National University of Defense Technology, Changsha 410000, China \\ ${ }^{2}$ Institute of Railway Research, University of Huddersfield, Huddersfield, UK \\ ${ }^{3}$ College of Intelligence Science and Technology, National University of Defense Technology, Changsha 410000, China
}

Correspondence should be addressed to Ruichen Wang; r.wang@hud.ac.uk

Received 15 December 2018; Revised 28 March 2019; Accepted 15 April 2019; Published 11 June 2019

Academic Editor: Angelo Marcelo Tusset

Copyright ( $\odot 2019$ Peng Zheng et al. This is an open access article distributed under the Creative Commons Attribution License, which permits unrestricted use, distribution, and reproduction in any medium, provided the original work is properly cited.

With the increasingly prominent energy issues, regenerative shock absorber has attracted intensive attention in last two decades for the development of structure design. However, the researchers sometimes concentrate on conceptual designs without considering optimal parameter refinements. This paper proposes a regenerative shock absorber called the "hydraulic electric regenerative shock absorber (HERSA)" which includes an analytical regeneration performance parameters optimisation approach to promote the regeneration efficiency and regenerated power. The developed HERSA model is able to convert oscillatory motion into unidirectional rotary motion through the alteration of hydraulic flow while recovering power by a generator. The proposed model is also capable of obtaining the optimal parameters at certain condition, as well as providing the flexibility of different component combinations to match specific system need. The results demonstrate that the proposed model can effectively decide the optimal parameters in the system, and also the recoverable power can achieve average power of $331 \mathrm{~W}$ at $1 \mathrm{~Hz}-25 \mathrm{~mm}$ sinusoidal excitation in the system, which is approximately $65 \%$ efficiency. This study can be further used to guide prototype design in future study.

\section{Introduction}

With the rapid development of the global economy, vehicles have been popularised by millions of households. However, the explosion of vehicles has also led to huge energy consumption and serious environmental pollution. For commercial vehicles, only $10 \%$ to $16 \%$ of the fuel energy has been utilised to provide proportion on driving. Most of the energy is wasted on road roughness and thermal exhaust. Among them, the kinetic energy loss by shock absorber/damper is the main energy dissipation [1]. In the past two decades, many researchers have done plenty studies on regenerative shock absorber to achieve the goal of energy recovery and the reduction of dissipation.

According to the discovery of the enormous potential for vibration energy recovery in automotive vehicles [2-5], researchers have been more interested in the study of vehicular regenerative shock absorbers. In 1996, Okada et al. [6, 7] proposed a regenerative suspension system. It is mainly used for active dampers to reduce energy dissipation. The shock absorber uses an electric actuator that can generate power at high driving speeds. In 2003, Nakano et al. $[8,9]$ proposed an electromagnetic damper which is composed of a DC motor, a planetary gear, and a ball screw mechanism. The DC motor can rotate in both directions to supply power and recover energy. The results show that the damper system can recover a certain amount of energy under the low-frequency and large-amplitude excitation conditions. However, under the conditions of highfrequency excitation, the suspension system has poor damping effect and less energy can be recovered. In 2005, Bose Corporation [10] developed an electromagnetic active suspension system. The system is equipped with a linear electromagnetic motor for each wheel. It can not only achieve the reduction of vibration but also recover a small amount of energy for reuse. It has a simple structure with a 
low cost but may be damaged for the small magnetic pole gap. In 2007, Zhang et al. [11] combined the ball screw system and DC motor to model a kind of power regeneration system. Under the excitation of sine wave input, this system can output the maximum voltage of $17.5 \mathrm{~V}$. In 2012, Li et al. [12] designed a built-in motion rectifier device for automotive suspension system. It converts the uncertain movement into the steady rotation of generator. The simulation shows that the regeneration efficiency is up to $60 \%$ and the power output is nearly $15 \mathrm{~W}$ when the vehicle travelled at a speed of $24 \mathrm{~km} / \mathrm{h}$. In 2013, Fang et al. [13] proposed a kind of hydraulic suspension system, which can achieve the active control by using a pump to adjust the pressure in hydraulic cylinder. In this system, the check valves are used to control the direction of oil flow to ensure the steady power output. In 2014, Fang et al. [14-16] developed a hydraulic electromagnetic shock absorber, which can regulate the fluid flow by applying a built-in hydraulic rectifier and internal accumulator in which the regeneration efficiency of the developed model is $16.6 \%$ at $10 \mathrm{~Hz} / 3 \mathrm{~mm}$ harmonic excitation. Li et al. [17] designed and fabricated a hydraulic shock absorber prototype with a hydraulic rectifier to characterise and identify the several key mechanical and electrical parameters of an electromechanical model. According to lack of model accuracy, the parameter assumptions in the electromechanical model cannot be always identified.

In general, the hydraulic electric regeneration shock absorber (HERSA) has attracted wide attention due to its stable work and compact structure [18], which is mainly integrated of hydraulic cylinder, check valves (rectifier modules), accumulators (stabilization modules), hydraulic motors (power conversion modules), and generators (power regeneration modules) [13-17, 19-22]. Some corresponding research studies have also been conducted based on the HERSA system. In 2015, Xu and Guo [19] applied the genetic algorithm in the power regenerating system to optimise the parameters of hydraulic pump. The results reveal that it can recover power of $33.4 \mathrm{~W}$, the excitation of sinusoidal wave is $1.67 \mathrm{~Hz}-50 \mathrm{~mm}$, and the regeneration efficiency is around $70 \%$. In 2016, Wang et al. [20] designed a novel regenerative hydraulic shock absorber system. A model which takes into account the impacts of the dynamics of hydraulic flow, rotational motion, and power regeneration is developed. It can be found that this system achieves recoverable power of $260 \mathrm{~W}$ with an efficiency of around $40 \%$ under sinusoidal excitation of $1 \mathrm{~Hz}$ and $25 \mathrm{~mm}$ amplitude when the accumulator capacity is set $0.32 \mathrm{~L}$ with the load resistance $20 \Omega$. In order to obtain a better damper performance in the hydraulic regenerative system, Ahmad and Alam [21] analysed the influences of applied components used in the system such as hydraulic cylinder, hydraulic motor, and hydraulic accumulator. In 2017, Zhang et al. [22] proposed a semiactive regenerative suspension system. This model takes into account the hydraulic losses in hydraulic system such as throttle resistance of valves, frictional resistance of pipelines, and resistance of motor.

In previous studies, it can be found that most research points on the HERSA mainly focus on the improvement of the modelling and experimental techniques but lack detailed research on parameter optimisation or optimal component combinations. A HERSA system is therefore proposed and studied in the following sections. This paper mainly focuses on the optimisation of power regeneration performance parameters and studies key parameters such as the hydraulic cylinder size, the check valve size, the accumulator capacity, the motor displacement, and the electrical load. Based on the principle of orthogonal test, the aim of the proposed HERSA is to find the optimal system parameters through modelling analysis to provide a reliable basis for the prototype design on variable applications, which can be universally used for general HERSA system.

As shown in Figure 1, this paper firstly introduces the vibration recovery potential and the modelling investigation of regeneration system. Secondly, the conceptual design of HERSA system is introduced, and then the model is created for optimising the parameters of key elements. Finally, the results of optimal component combinations are pointed out and then the dynamic behaviours of the HERSA are discussed and validated. Based on the orthogonal test method, a power regeneration optimisation method for general HERSA system is also proposed in this paper.

\section{System Modelling of HERSA}

2.1. Design Concept. To understand the mechanism of a regenerative shock absorber system, a mathematical model is designed on the basis of a typical configuration of the shock absorber.

As shown in Figure 2, a schematic design of the HERSA is proposed which consists of a hydraulic cylinder, four check valves, a hydraulic accumulator, a hydraulic motor, a permanent magnetic generator, pipelines, battery, and an oil tank. The key component of the system is the hydraulic cylinder that represents a conventional shock absorber or damper.

When the piston of hydraulic cylinder moves up and down due to the excitation, the shock oil in cylinder can be forced to flow through one-way valve and hydraulic accumulator and drive the hydraulic motor. By the regulating effect of check valves, the fluid flow will pass through the motor in one direction. Meanwhile, the accumulator's smoothing effect delivers a stable fluid flow to provide hydraulic motor a more reliable and stable working condition. Driven by the pressurised flow, the hydraulic motor converts linear motion into rotary motion as a motion converter, which will also drive the DC generator for the purpose of power regeneration. Finally, the power regenerated will be stored in battery or charged vehicle-mounted equipment.

2.2. Hydraulic Flows. The road excitation is normally consisted by numerous sinusoidal waves [23]. In order to simplify the model, the excitation is considered as the sinusoidal wave, which is defined as the fundamental element of road irregularity. Therefore, the movement of piston is expressed by 


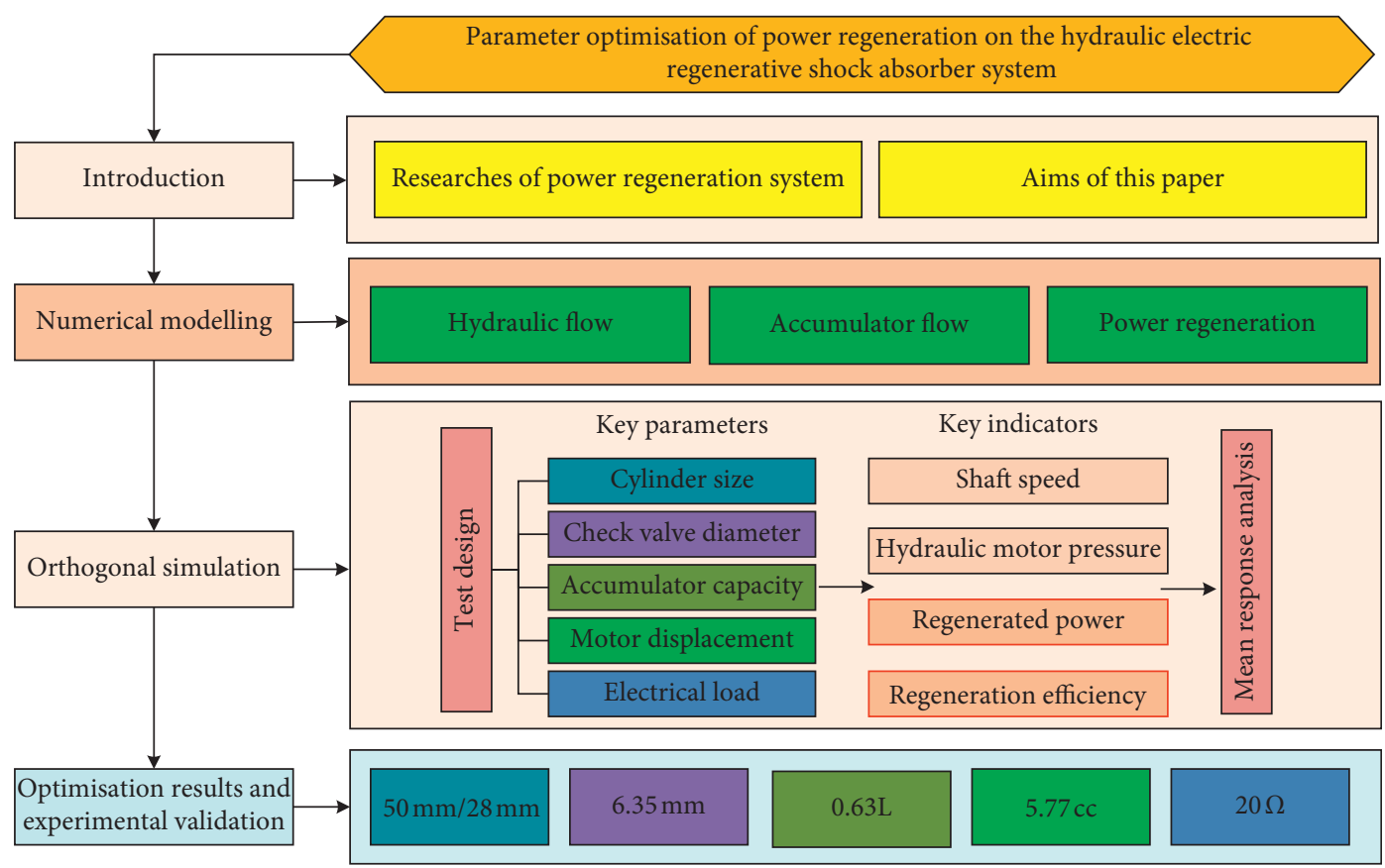

FIgURE 1: The study procedures of the HERSA.

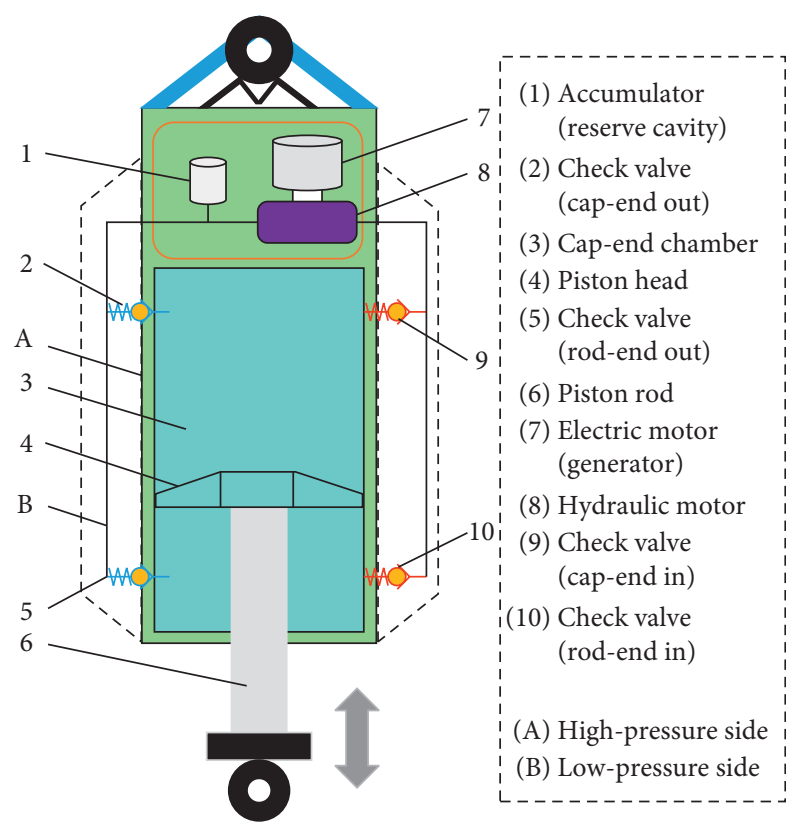

FIgURE 2: Diagram view of the design concept for HERSA.

$$
X_{\mathrm{a}}(t)=X \sin (2 \pi f t),
$$

where $f$ is the excitation frequency and $X$ is the maximum amplitude. When the shaft moves up and down, the volume change of cap-end chamber $V_{\mathrm{A}}$ and rod-end chamber $V_{\mathrm{B}}$ can be calculated by

$$
\left\{\begin{array}{l}
V_{\mathrm{A}}=A_{\mathrm{A}}\left(X_{0} \mp X_{\mathrm{a}}\right)+V_{\text {cyd }}, \\
V_{\mathrm{B}}=A_{\mathrm{B}}\left(X_{0} \pm X_{\mathrm{a}}\right)+V_{\text {cyd }},
\end{array} \quad\right. \text { up and down, }
$$

$V_{\text {cyd }}$ is dead volume which refers to the fluid volume in the cylinder chambers at zero position. It is considered as the necessary part of volume change. In addition, $A_{\mathrm{A}}$ and $A_{\mathrm{B}}$ are the areas of cap-end and rod-end on both sides of piston. $X_{0}$ refers to the starting level of the piston.

The processes of fluid flows in designed hydraulic system are shown in Figure 3. According to Bernoulli's principle,

$$
P+\frac{\rho v_{f}^{2}}{2}+\rho g h=\text { constant }
$$

where $P$ is the pressure, $\rho$ is the fluid density, $v_{\mathrm{f}}$ is the flow speed, and $h$ is the elevation of the point above a reference plane. The flow in cylinder and check valves can be expressed by

(a) Outflow of cylinder:

$$
\begin{cases}Q_{\text {Aout }}=C_{\mathrm{C}} A_{\mathrm{C}} \sqrt{\frac{2\left|P_{\mathrm{A}}-P_{\mathrm{M}}\right|}{\rho}}, & P_{\mathrm{A}}>P_{\mathrm{M}}, \\ Q_{\text {Bout }}=C_{\mathrm{C}} A_{\mathrm{C}} \sqrt{\frac{2\left|P_{\mathrm{B}}-P_{\mathrm{M}}\right|}{\rho}}, & P_{\mathrm{B}}>P_{\mathrm{M}} .\end{cases}
$$

(b) Inflow of cylinder:

$$
\begin{cases}Q_{\text {Ain }}=C_{\mathrm{C}} A_{\mathrm{C}} \sqrt{\frac{2\left|P_{\mathrm{M}}-P_{\mathrm{A}}\right|}{\rho}}, & P_{\mathrm{M}}>P_{\mathrm{A}}, \\ Q_{\text {Bin }}=C_{\mathrm{C}} A_{\mathrm{C}} \sqrt{\frac{2\left|P_{\mathrm{M}}-P_{\mathrm{B}}\right|}{\rho}}, & P_{\mathrm{M}}>P_{\mathrm{B}},\end{cases}
$$

$C_{\mathrm{C}}$ and $A_{\mathrm{C}}$ are the flow coefficient and the area of inline check valve port. $P_{\mathrm{A}}, P_{\mathrm{B}}$, and $P_{\mathrm{M}}$ represent the pressures 


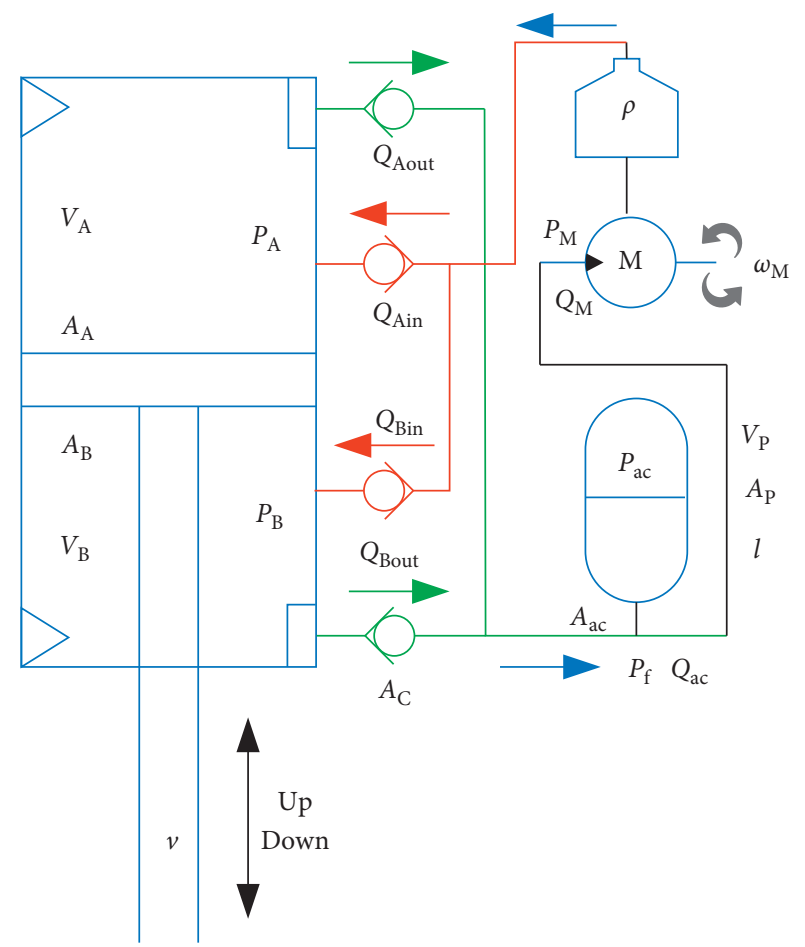

FIgURE 3: Schematic view of fluid flows in hydraulic system.

at the cap-end chamber, the rod-end chamber, and the motor inlet, respectively.

According to the influence of fluid compressibility in hydraulic elements, the pressure out of the cylinder during the piston motion can be simultaneously expressed:

(a) Up stroke:

$$
\dot{P}_{\mathrm{A}}=\frac{\beta_{\mathrm{A}}\left(A_{\mathrm{A}} v(t)-Q_{\text {Aout }}+Q_{\text {Ain }}\right)}{V_{\mathrm{A}}},
$$

(b) Down stroke:

$$
\dot{P}_{\mathrm{B}}=\frac{\beta_{\mathrm{B}}\left(A_{\mathrm{B}}(-v(t))-Q_{\text {Bout }}+Q_{\text {Bin }}\right)}{V_{\mathrm{B}}},
$$

$\beta_{\mathrm{A}}$ and $\beta_{\mathrm{B}}$ are the effective bulk modulus in cap-end chamber and rod-end chamber.

In general, there are many empirical formulas for the effective bulk modulus. Given the relatively low pressure in the HERSA system (under 100 bar), Boes's model [24] is applied to determine the bulk modulus of the fluid in the cylinder and motor:

$$
\beta=\beta_{\text {ref }} \cdot \frac{\log \left(99 P / P_{\text {ref }}+1\right)}{2} .
$$

According to the variations of the cylinder chambers (cap-end and rod-end chambers), the fluid flow rate and pressure in those two chambers can also oscillated significantly. An accumulator is therefore used at the inlet of motor, and the flow volume $V_{\text {acf }}$ in accumulator can be written as

$$
V_{\mathrm{acf}}=V_{\mathrm{ac}}\left(1-\frac{P_{\mathrm{ac}}}{P_{\mathrm{f}}}\right)^{1 / k}, \quad P_{f}>P_{\mathrm{ac}},
$$

where $V_{\mathrm{ac}}$ is the volume of accumulator, $P_{\mathrm{ac}}$ is precharged pressure to accumulator, $P_{\mathrm{f}}$ is the fluid pressure of the accumulator, and $k$ is the gas specific heat ratio of gas-charged accumulator, and the fluid flow of accumulator can be written as

$$
Q_{\mathrm{ac}}=C_{\mathrm{ac}} A_{\mathrm{ac}} \operatorname{sgn}\left(P_{\mathrm{M}}-P_{\mathrm{f}}\right) \sqrt{\frac{2\left|P_{M}-P_{f}\right|}{\rho}},
$$

where $C_{\mathrm{ac}}$ is the accumulator flow coefficient and $A_{\mathrm{ac}}$ is the area of the accumulator inlet port. The volume variation of accumulator fluid $V_{\mathrm{p}}$ is

$$
V_{\mathrm{p}}=\frac{-k P_{\mathrm{f}} \mathrm{Q}_{\mathrm{ac}}}{\dot{P}_{\mathrm{f}}} \text {. }
$$

Considering the smoothing effect of hydraulic accumulator, a more accurate model of hydraulic motor can be determined including the variations of accumulator fluid flow and volume. Therefore, the pressure and fluid flow of hydraulic motor can be represented:

$$
\begin{aligned}
\dot{P}_{\mathrm{M}} & =\frac{\beta_{\mathrm{M}}\left(Q_{\text {Aout }}+Q_{\text {Bout }}-Q_{\mathrm{ac}}-Q_{\mathrm{M}}\right)}{V_{\mathrm{T}}}, \\
Q_{\mathrm{M}} & =\frac{D_{\mathrm{M}} \omega_{\mathrm{M}}}{2 \pi},
\end{aligned}
$$

where $\beta_{\mathrm{M}}$ is the effective bulk modulus of the motor chamber, $D_{\mathrm{M}}$ is the displacement of the hydraulic motor, and $\omega_{M}$ is the shaft speed of the hydraulic motor and generator, respectively.

2.3. Power Regeneration. Driven by the fluid flow, the hydraulic motor can produce rotary motion which is able to drive the DC generator to produce electricity. The working process of power regeneration is shown in Figure 4.

Where the mechanical efficiency of motor is $\eta_{\mathrm{M}}$, the driving torque of motor $T_{M}$ is

$$
T_{\mathrm{M}}=\frac{D_{\mathrm{M}} P_{\mathrm{M}} \eta_{\mathrm{M}}}{2 \pi} \text {. }
$$

According to Newton's second law of motion, the rotary motion $\omega_{\mathrm{m}}$ is

$$
\dot{\omega}_{\mathrm{M}}=\frac{\left(T_{\mathrm{M}}-T_{\mathrm{G}}\right)}{J_{\mathrm{t}}},
$$

where $J_{\mathrm{t}}$ is the shaft moment of inertia. In addition, the electromagnetic torque of generator $T_{\mathrm{G}}$ would change with the variation in the induced current, and it is considered as the resistance torque because it provides the rotation to the motor in an opposite direction. Therefore, it can be written as

$$
T_{\mathrm{G}}=K_{\mathrm{T}} I \text {. }
$$

The electromotive force (EMF) can be expressed as

$$
E=K_{\mathrm{E}} \omega_{\mathrm{M}} \text {, }
$$




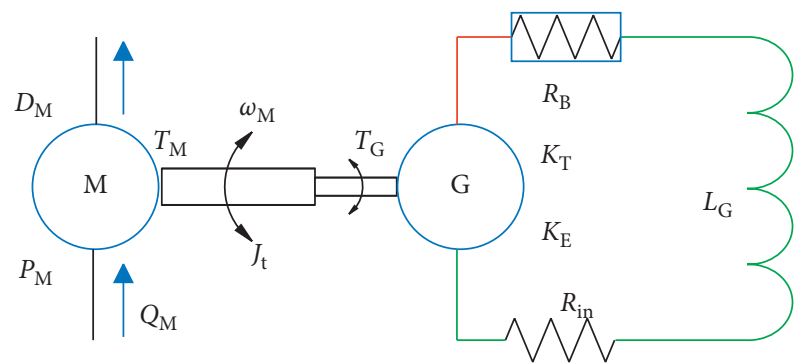

Figure 4: Schematic view of energy conversion (mechanical to electrical) and power circuit.

where $K_{\mathrm{T}}$ is torque constant coefficient and $K_{\mathrm{E}}$ is the electromotive voltage constant coefficient.

According to Kirchhoff's voltage law [25], assuming that the susceptibility at any temperature and the flux that is established by the PM poles are constant, the variation in current can be calculated by

$$
\dot{I}=\frac{\left(E-\left(R_{\mathrm{in}}+R_{\mathrm{B}}\right) I\right)}{L_{\mathrm{G}}},
$$

where $L_{\mathrm{G}}$ is the internal inductance, $R_{\mathrm{B}}$ is the external electrical load of battery, and $R_{\text {in }}$ is the internal resistance of generator. Then, the instantaneous voltage can be expressed as

$$
U=I R_{\mathrm{B}}
$$

Therefore, the output of regenerated power is

$$
P_{\text {out }}=I^{2} R_{\mathrm{B}}=\frac{U^{2}}{R_{\mathrm{B}}} .
$$

In addition, the effective input power of this system is considered as the sum of the piston damping force multiplied by the effective piston area. Given the areas of cap-end and rod-end are known, the piston damping force can be written as

$$
\left\{\begin{array}{l}
F_{\mathrm{A}}=P_{\mathrm{A}} A_{\mathrm{A}}, \\
F_{\mathrm{B}}=P_{\mathrm{B}} A_{\mathrm{B}} .
\end{array}\right.
$$

Therefore, the input power of the HERSA system is

$$
P_{\text {in }}=P_{\mathrm{A}} A_{\mathrm{A}}|v(t)|+P_{\mathrm{B}} A_{\mathrm{B}}|v(t)|, \quad \text { up + down. }
$$

Hence, the power regeneration efficiency can be calculated from the following equation:

$$
\eta_{\text {reg }}=\frac{P_{\text {out }}}{P_{\text {in }}}
$$

\section{Simulation of HERSA}

This study focuses on the effect of the key parameters which include the sizes of shock absorber body, the size of check valve port, hydraulic motor displacement, and hydraulic accumulator capacity. Hence, the investigation is performed on the proposed parameter optimisation method to study the HERSA's behaviour and power level, as well as the desirable parameter solutions.
3.1. Parameters Setting and Study. In the modelling, a few assumptions made during this process were as follows:

(a) There are no additional electrical losses in generator configuration to be considered. It means the output power of hydraulic motor is equal to the input power of generator.

(b) The cylinder internal leakage between the chambers is not accounted for by the model.

(c) The external electrical load (battery/resistor) has no influence by the varying temperature.

(d) Fluid compressibility is defined as using Boes's model in hydraulic system.

In practical applications, there are various types of losses in HERSA system, such as hydraulic motor internal flow leakage, pressure loss in the pipeline, check valve pressure loss, and hydraulic cylinder piston friction.

To simplify the model, the impact of these losses and influences in the system are not taken into account at this stage. Therefore, the model is ideally configured and the following main parameters are selected.

3.1.1. Size of the Hydraulic Cylinder. In this system, the hydraulic cylinder is applied to replace the traditional shock absorber and absorb vibration energy. This paper takes 4x4 SUV "Beijing Jeep 2021" as the example and determines that the maximum stroke of cylinder is $200 \mathrm{~mm}$. The sizes of the shock absorber body are determined according to the standard, ISO 3320-2013 [26]; it is well known that a conventional viscous shock absorber has asymmetrical damping characteristic due to its inherent design structure which can provide different damping forces during the compression and extension strokes. The piston diameter and rod diameter are therefore determined as Table 1.

3.1.2. Size of the Check Valve Port. The fluid pressurised by the oscillation flows through check valve arrangement to ensure fluid always flows through hydraulic motor in one direction and enable the chambers in the cylinder can be replenished as fast as possible for each run. In terms of the standard port size on double-acting cylinder, the common sizes of check valves are shown in Table 2 .

3.1.3. Hydraulic Accumulator Capacity. A common hydraulic accumulator is used to minimise the fluctuation of the pressurised flow. Initially, the gas chamber is precharged to pressure Pac and set to 20 bar.

In equations (9)-(11), several assumptions have been made to simplify the hydraulic accumulator model:

(a) The accumulator is set as a diaphragm type accumulator without heat exchange during the process.

(b) There is a transient pressure balance inside the accumulator between fluid chamber and gas chamber.

(c) Frictions and thermal losses are neglected here. 
TABLE 1: Hydraulic cylinder specification.

\begin{tabular}{lcccc}
\hline Factor $A$ & Level 1 & Level 2 & Level 3 & Level 4 \\
\hline Piston diameter $(\mathrm{mm})$ & 50 & 40 & 32 & 25 \\
Rod diameter $(\mathrm{mm})$ & 28 & 25 & 20 & 16 \\
\hline
\end{tabular}

(d) Only fully charged and fully discharged states are considered in the hydraulic model.

(e) The precharge pressure in the accumulator is set at $60 \%$ of the working pressure (20 bar) to provide pressure pulsation damping.

According to the damping forces in a traditional shock absorber in a SUV, the accumulator capacity has been estimated with a peak of 100 bar, which is shown in Table 3.

3.1.4. Hydraulic Motor Displacement. The hydraulic motor is defined as a transfer device which is able to convert the unidirectional hydraulic flow/pressure into rotational motion/torque. Its main parameters are shown in Table 4.

3.1.5. External Electrical Load. For the regenerative shock absorber, the electrical load has significant effects on the capability of power regeneration and the dynamics of the system [1], and it can be considered as Table 5 .

3.1.6. Other Key Parameters. As shown in Table 6, the values of several other parameters are displayed.

3.2. Orthogonal Simulation Test Design. The orthogonal test design is an important approach of statistical evaluation, which can reduce the number of attempts and then effectively obtain desired results [27]. Large-scale engineering testing is a complex system engineering. There are many factors influencing the test results: some factors play an independent role, and some factors can interact with others to produce the comprehensive effect. The reason that affects the results during the test is called the test factor, and the state adopted under each factor is called the level. Starting from Section 3.1, five-factor and four-level conditions have been applied in this test, as shown in Table 7. The simplest method is to apply an exhaustive method to test all factors and levels at the same time.

As shown in Table 7, the designed test has four 4-level factor and one 2-level factor. If all factors and their levels achieve their best performance for integration testing, then the total of 512 tests need to be performed. Obviously, a large number of tests definitely demand a lot of manpower and material resources as well as take a long time to reach the target. Therefore, this paper focuses on the problem that how to reasonably arrange the test and obtain the necessary indication through less number of tests. The orthogonal method is an effective mathematical method to solve the problem of multifactor test. It also applies the orthogonal table design scheme and the mathematical statistics method to analyse the test data. However, the $L_{16}\left(4^{4} \times 2\right)$ orthogonal table (Table 8 ) is designed for the simulation test of HERSA
TABLE 2: Check valves specification.

\begin{tabular}{lcccc}
\hline Factor $B$ & Level 1 & Level 2 & Level 3 & Level 4 \\
\hline Check valve diameter $(\mathrm{mm})$ & 6.35 & 9.525 & 12.7 & 19.05 \\
\hline
\end{tabular}

TABLE 3: Hydraulic accumulator specification.

\begin{tabular}{lcc}
\hline Factor $C$ & Level 1 & Level 2 \\
\hline Accumulator capacity (L) & 0.63 & 1 \\
\hline
\end{tabular}

Table 4: Hydraulic motor displacement.

\begin{tabular}{lcccc}
\hline Factor $D$ & Level 1 & Level 2 & Level 3 & Level 4 \\
\hline Motor displacement $(\mathrm{cc})$ & 5.77 & 7.07 & 8.01 & 8.94 \\
\hline
\end{tabular}

TABLE 5: Battery/Resistor resistance.

\begin{tabular}{lcccc}
\hline Factor $E$ & Level 1 & Level 2 & Level 3 & Level 4 \\
\hline Electrical load $(\Omega)$ & 10 & 20 & 30 & 40 \\
\hline
\end{tabular}

TABle 6: Other key specifications of the HERSA.

\begin{tabular}{lcc}
\hline Symbol & Value & Unit \\
\hline$f$ & 1 & $\mathrm{~Hz}$ \\
$X_{\mathrm{a}}$ & 25 & $\mathrm{~mm}$ \\
$\rho$ & 872 & $\mathrm{~kg} / \mathrm{m}^{3}$ \\
$C_{\mathrm{C}}$ & 0.7 & - \\
$X_{0}$ & 200 & $\mathrm{~mm}$ \\
$l$ & 1 & $\mathrm{~m}$ \\
$\beta_{\text {ref }}$ & $1.2 \times 10^{9}$ & - \\
$P_{\text {ref }}$ & 20 & $\mathrm{bar}$ \\
$k$ & 1.4 & - \\
$\eta_{\mathrm{m}}$ & 100 & $\%$ \\
$J_{\mathrm{t}}$ & 0.003 & $\mathrm{~kg} \cdot \mathrm{m}^{2}$ \\
$K_{\mathrm{T}}$ & 0.65 & - \\
$K_{\mathrm{E}}$ & 0.65 & - \\
$R_{\mathrm{in}}$ & 7.5 & $\Omega$ \\
$L_{\mathrm{G}}$ & 0.03 & $\mathrm{H}$ \\
$V_{\mathrm{agd}}$ & $0.1 \% \mathrm{~L}$ \\
$D_{\mathrm{ac}}$ & $\mathrm{D}_{\mathrm{cv}}$ & $\mathrm{mm}$ \\
$C_{\mathrm{ac}}$ & 0.7 & - \\
\hline
\end{tabular}

TABLe 7: Simulation test combinations.

\begin{tabular}{lccccc}
\hline Level & \multicolumn{5}{c}{ Factor } \\
& $A(\mathrm{~mm})$ & $B(\mathrm{~mm})$ & $C(\mathrm{~L})$ & $D(\mathrm{cc})$ & $E(\Omega)$ \\
\hline Level 1 & $50 / 28$ & 6.35 & 0.63 & 5.77 & 10 \\
Level 2 & $40 / 25$ & 9.525 & 1 & 7.07 & 20 \\
Level 3 & $32 / 20$ & 12.7 & - & 8.01 & 30 \\
Level 4 & $25 / 16$ & 19.05 & - & 8.94 & 40 \\
\hline
\end{tabular}

[28], and only 16 tests need to be carried out. It is obvious that the proposed parameter optimisation method can effectively improve the efficiency of simulation and fastly obtain the required simulation results.

According to the above test design table, numerical simulation is carried out in mathematical model. A sinusoidal excitation $1 \mathrm{~Hz}-25 \mathrm{~mm}$ is set as predefined input. All other parameters are kept the same as in Table 6. 
TABLE 8: Orthogonal simulation test design list $L_{16}\left(4^{4} \times 2\right)$.

\begin{tabular}{lccccc}
\hline \multirow{2}{*}{ No. } & $A(\mathrm{~mm})$ & $B(\mathrm{~mm})$ & $C(\mathrm{~L})$ & $D(\mathrm{cc})$ & $E(\Omega)$ \\
\hline Test 1 & $50 / 28$ & 6.35 & 0.63 & 5.77 & 10 \\
Test 2 & $50 / 28$ & 9.525 & 0.63 & 7.07 & 20 \\
Test 3 & $50 / 28$ & 12.7 & 1 & 8.01 & 30 \\
Test 4 & $50 / 28$ & 19.05 & 1 & 8.94 & 40 \\
Test 5 & $40 / 25$ & 6.35 & 1 & 7.07 & 30 \\
Test 6 & $40 / 25$ & 9.525 & 1 & 5.77 & 40 \\
Test 7 & $40 / 25$ & 12.7 & 0.63 & 8.94 & 10 \\
Test 8 & $40 / 25$ & 19.05 & 0.63 & 8.01 & 20 \\
Test 9 & $32 / 20$ & 6.35 & 0.63 & 8.01 & 40 \\
Test 10 & $32 / 20$ & 9.525 & 0.63 & 8.94 & 30 \\
Test 11 & $32 / 20$ & 12.7 & 1 & 5.77 & 20 \\
Test 12 & $32 / 20$ & 19.05 & 1 & 7.07 & 10 \\
Test 13 & $25 / 16$ & 6.35 & 1 & 8.94 & 20 \\
Test 14 & $25 / 16$ & 9.525 & 1 & 8.01 & 10 \\
Test 15 & $25 / 16$ & 12.7 & 0.63 & 7.07 & 40 \\
Test 16 & $25 / 16$ & 19.05 & 0.63 & 5.77 & 30 \\
\hline
\end{tabular}

3.3. Simulation Results and Discussion. To use the model with orthogonal test approach developed in Sections 3.1 and 3.2 for subsequent studies on the improvement of parameter optimisation, this section firstly presents studies on the investigation of key model parameters based on modelling analysis. Then, it shows the quantitative behaviours (pressure, shaft speed, regenerated power, and regeneration efficiency) of the system under designed test table, gaining a preliminary understanding of the system behaviours. However, the key results are summarised in Table 9. According to the principle of orthogonal test, the averages of outputs are calculated in the mean response analysis.

As shown in Figure 5, the variation of the motor shaft speed, pressure, mechanical power, and regenerated power is dramatically levelled up at larger cylinder size with lower motor displacement, accumulator capacity, the size of check valve, and external load resistance. The averages of those results are shown in Table 9. It is also clear that the change of component combination can significantly affect the system dynamics and regenerated power level to meet the demands of various vehicle suspension systems. By changing the component combinations, the maximum regenerated power of $417.5 \mathrm{~W}$ with the regeneration efficiency of approximately $53.4 \%$ can be achieved on test 1 . It is also obvious that the highest regeneration efficiency occurs at test 16 (approximately $63 \%$ ) which is designed with small size of cylinder, motor displacement, accumulator capacity, and large check valve port. Additionally, the results of those 16 tests reveal that the change of motor displacement, external loads, and accumulator capacity is capable of smoothing the flow oscillations and allow effective minimisation to the instability of hydraulic circuit, thus altering the performance of the system and power capability.

It can be summarised that the change of component combinations can not only affect the stability of system dynamics but also dramatically impact on the level of regenerated power.

\section{Parameter Optimisation Analysis}

16 sets of simulation tests have been designed and performed to provide desirable solutions of the system parameters to enhance the system behaviours and power level. After that, mean response analysis is used to take the average value of all test results for each factor level and determine the extent that the factor affects the indicator based on the range mean values, which is called the comprehensive equilibrium method. It can be applied to perform the multi-indicator analysis of shaft speed, hydraulic motor pressure, regenerative power, and regeneration efficiency.

4.1. Shaft Speed. As shown in Figure 6, the size of cylinder has the greatest influence on shaft speed with a visibly large range. The larger cylinder size can deliver faster flow which is capable of providing larger rotational torque on motor shaft. The smaller motor displacement is also beneficial on the motor rotation, which is more effective than other three factors. Compared to the size of check valves, the electrical load has an equivalent degree of influence to the shaft speed. In addition, it is obvious that the capacity of accumulator is less significant than other factors for shaft speed. It can be concluded that the optimal combination of the shaft speed as the evaluation criterion is $A_{1} B_{1} C_{1} D_{1} E_{1}$, where $A_{1}=50 /$ $28 \mathrm{~mm}, \quad B_{1}=6.35 \mathrm{~mm}, \quad C_{1}=0.63 \mathrm{~L}, \quad D_{1}=5.77 \mathrm{cc}, \quad$ and $E_{1}=10 \Omega$.

4.2. Hydraulic Motor Pressure. As shown in Figure 7, the displacement of motor and the load of generator have almost equivalent influences on working pressure, and they take slightly lower impacts in comparison to the size of hydraulic cylinder. Additionally, it reveals that smaller check valve diameter can significantly lead to higher pressure. The higher average pressure means much more power can be produced by the generator to raise the regenerated power level. Therefore, optimal combination of hydraulic motor pressure is $A_{1} B_{1} C_{1} D_{1} E_{1}$, where $A_{1}=50 / 28 \mathrm{~mm}, B_{1}=6.35 \mathrm{~mm}$, $C_{1}=0.63 \mathrm{~L}, D_{1}=5.77 \mathrm{cc}$, and $E_{1}=10 \Omega$.

4.3. Regenerated Power. As shown in Figure 8, the size of the cylinder has significant influence on the power output of the power circuit which is more important than other factors. Obviously, the small values of other factors can also contribute positive effects for more regenerated power. From the mean response analysis of Figure 8 , the optimal combination of the regenerated power is $A_{1} B_{1} C_{1} D_{1} E_{1}$, where $A_{1}=50 /$ $28 \mathrm{~mm}, B_{1}=6.35 \mathrm{~mm}, C_{1}=0.63 \mathrm{~L}, \quad D_{1}=5.77 \mathrm{cc}$, and $E_{1}=10 \Omega$.

4.4. Regeneration Efficiency. Regeneration efficiency is a significant indicator to assess the performance of HERSA. As shown in Figure 9, the electrical load has the greatest influence on the regeneration efficiency. When the electrical load is $20 \Omega$, the proposed system can reach a high regeneration efficiency, which increases slowly with the larger value of electrical load. Compared to other three indicators, 
TABLE 9: Summary of simulation tests.

\begin{tabular}{|c|c|c|c|c|c|}
\hline Test no. & Shaft speed (rpm) & Hydraulic motor pressure (bar) & Input power $(\mathrm{W})$ & Regenerated power (W) & Regeneration efficiency \\
\hline Test 1 & 1651.3928 & 46.4087 & 781.801 & 417.5 & 0.53402 \\
\hline Test 2 & 1340.0569 & 19.8006 & 342.7223 & 223.9 & 0.65334 \\
\hline Test 3 & 1175.6696 & 11.384 & 204.1776 & 139.8 & 0.68482 \\
\hline Test 4 & 1055.314 & 7.317 & 137.1768 & 94.2 & 0.68667 \\
\hline Test 5 & 810.6328 & 8.8879 & 101.5277 & 66.43 & 0.65427 \\
\hline Test 6 & 988.5237 & 10.621 & 117.1773 & 82.61 & 0.70496 \\
\hline Test 7 & 665.2814 & 11.886 & 129.5599 & 66.65 & 0.50674 \\
\hline Test 8 & 727.5167 & 9.4879 & 65.9557 & 65.96 & 0.62528 \\
\hline Test 9 & 461.2982 & 3.5676 & 30.0727 & 17.98 & 0.59788 \\
\hline Test 10 & 410.7713 & 3.5638 & 29.6083 & 17.06 & 0.57626 \\
\hline Test 11 & 648.1021 & 11.7337 & 81.8903 & 52.31 & 0.63877 \\
\hline Test 12 & 531.5388 & 12.1918 & 84.7933 & 43.18 & 0.50923 \\
\hline Test 13 & 251.6925 & 2.9404 & 15.4995 & 7.888 & 0.5089 \\
\hline Test 14 & 284.2986 & 5.7556 & 26.3095 & 12.35 & 0.46945 \\
\hline Test 15 & 312.0371 & 2.7366 & 14.5937 & 8.228 & 0.56378 \\
\hline Test 16 & 388.8416 & 5.2267 & 24.2388 & 15.28 & 0.63042 \\
\hline
\end{tabular}

higher regeneration efficiency can be found with larger the size of check valve port and the capacity of accumulator. It is clear that the larger size of hydraulic cylinder also contributes to regeneration efficiency. However, the optimal combination of regeneration efficiency is $A_{1} B_{4} C_{2} D_{1} E_{4}$, where $A_{1}=50 / 28 \mathrm{~mm}, B_{4}=19.05 \mathrm{~mm}, C_{2}=1 \mathrm{~L}, D_{1}=5.77 \mathrm{cc}$, and $E_{4}=40 \Omega$.

4.5. Optimisation Results. From the mean response analysis of Figures 6-9, it can be concluded that the optimal combination of each parameter for more regenerated power on the HERSA is $A_{1} B_{1} C_{1} D_{1} E_{1}$. However, a high regeneration efficiency is also one of the important criteria. It is necessary to adjust the optimal combination for the higher regeneration efficiency. According to the range mean values of different factors, the extent that the factor affects the indicator can be determined. The rank of factors based on their degree of importance and their corresponding best combination are shown in Table 10.

It is obvious that the largest size of cylinder $\left(A_{1}\right)$ and the smallest displacement of motor $\left(D_{1}\right)$ can provide better dynamics and power level for the proposed HERSA. According to the principle of the comprehensive equilibrium method, the selection of other factors is as follows:

(a) Given the rank of factor B on different indicators is fourth, the superior level selection is considered as the one that occurs most frequently. The selection of factor $B$ therefore is level 1 , where $B_{1}=6.35 \mathrm{~mm}$.

(b) Identically, the rank of factor $C$ is fifth on different indicators. Given the best level selection of factor $C$ for three indicators is level 1 , which is the one that occurs most frequently. Therefore, the selection of factor $C$ is level 1 , where $C_{1}=0.63 \mathrm{~L}$.

(c) When the factor has a different degree of influence on all indicators, the more important indicators should be satisfied firstly. The regeneration efficiency and regenerated power are the main criteria of this system. When the factor $E$ is selected, the level 2 may be better. As shown in Figures 8 and 9, the efficiency at level 2 is over $60 \%$, which is much higher than that at level 1 and nearly to that at level 3 and 4 . Meanwhile, the regenerated power at level 2 is also high. The selection of factor $E$ is level 2, where $E_{2}=20 \Omega$.

Therefore, the optimal combination of parameters in HERSA is $A_{1} B_{1} C_{1} D_{1} E_{2}$, which is capable of delivering a large electrical power as well as a high regeneration efficiency. The optimisation results are shown as follows: The size of cylinder is $50 \mathrm{~mm}$ (piston) and $28 \mathrm{~mm}$ (rod), the diameter of check valve is $6.35 \mathrm{~mm}$, the accumulator capacity is $0.63 \mathrm{~L}$, the displacement of motor is $5.77 \mathrm{cc}$, and the electrical load of generator is $20 \Omega$, respectively. Furthermore, for the general HERSA system (including hydraulic cylinders, check valves, accumulators, motors, and generators), a set of optimisation methods about power regeneration performance can be summarised as follows:

(a) Determine the range of key parameters

(b) Design the corresponding orthogonal test

(c) Conduct the mean response analysis

(d) Discuss the optimisation results

It is considered that the proposed optimisation procedure is suitable for the general HERSA system. Figure 10 shows the results of the HERSA applied with the optimal component combinations.

As shown in Figure 10, the shaft speed is $1634 \mathrm{rpm}$, the accumulator pressure is about $30 \mathrm{bar}$, the power output is about $331 \mathrm{~W}$, and the regeneration efficiency is approximately 65\%. Both larger power and higher regenerated efficiency are achieved.

4.6. Experimental Validation. The setup of the test rig is shown in Figure 11. According to the schematic in Figure 3, the parameters of the key components are listed in Tables 6 and 11. A corresponding test rig was designed and fabricated according to the design concept and model development to validate the prediction of the optimised HERSA model. Based on the result of parameter optimisation, the 


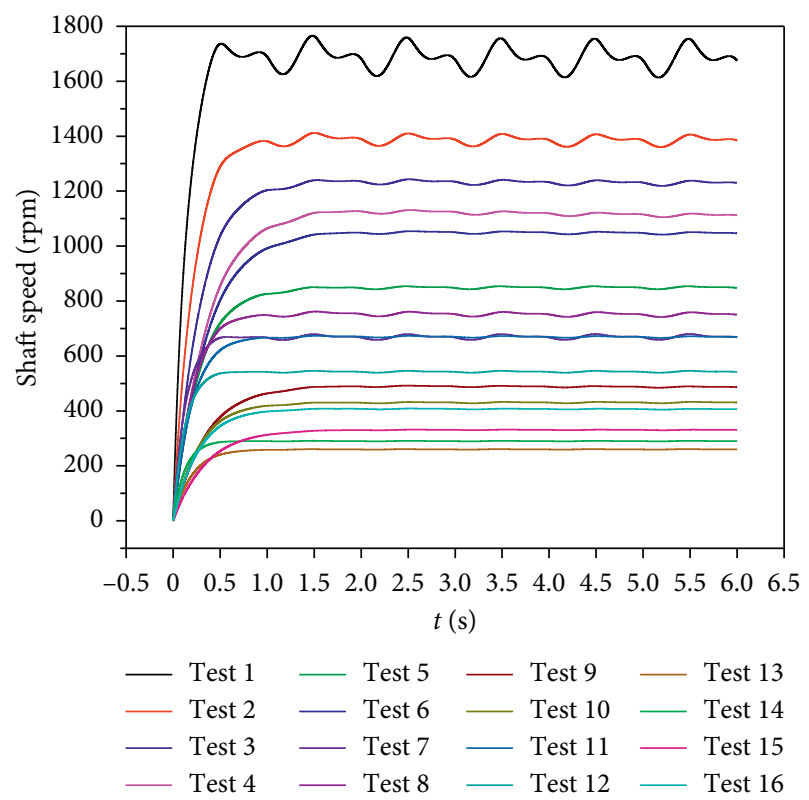

(a)

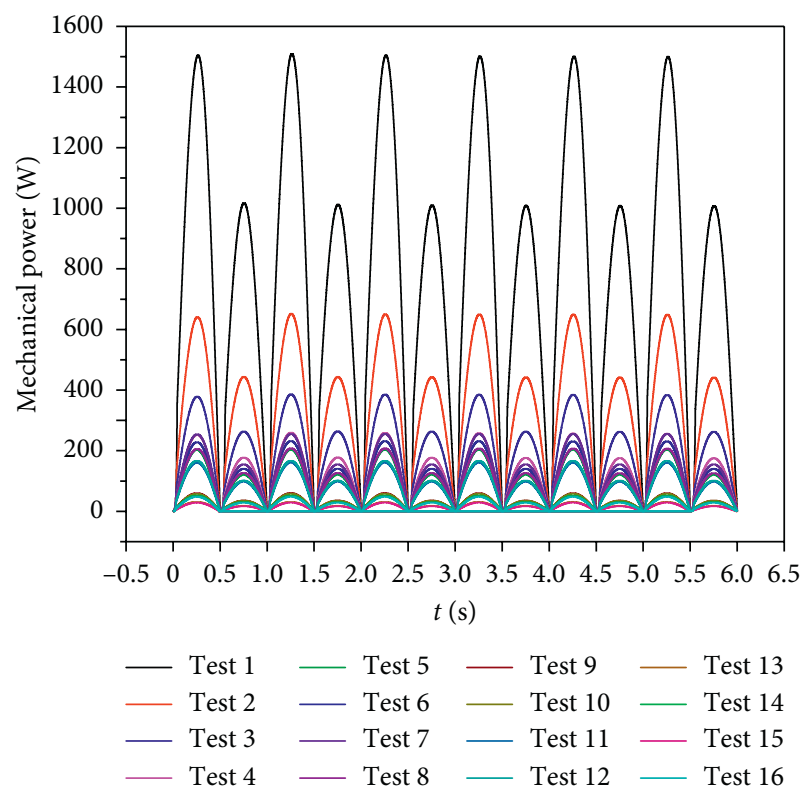

(c)

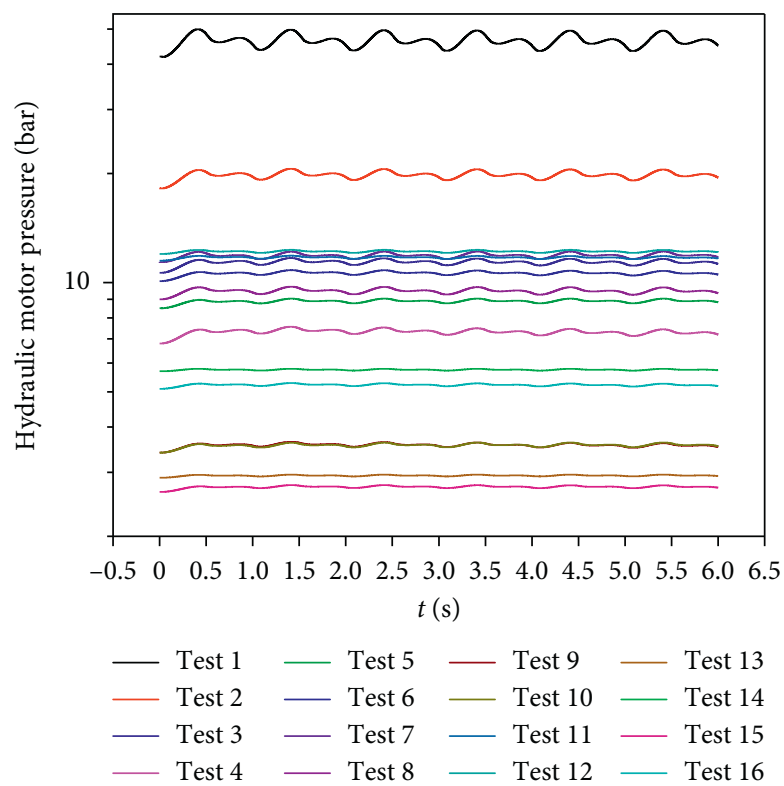

(b)

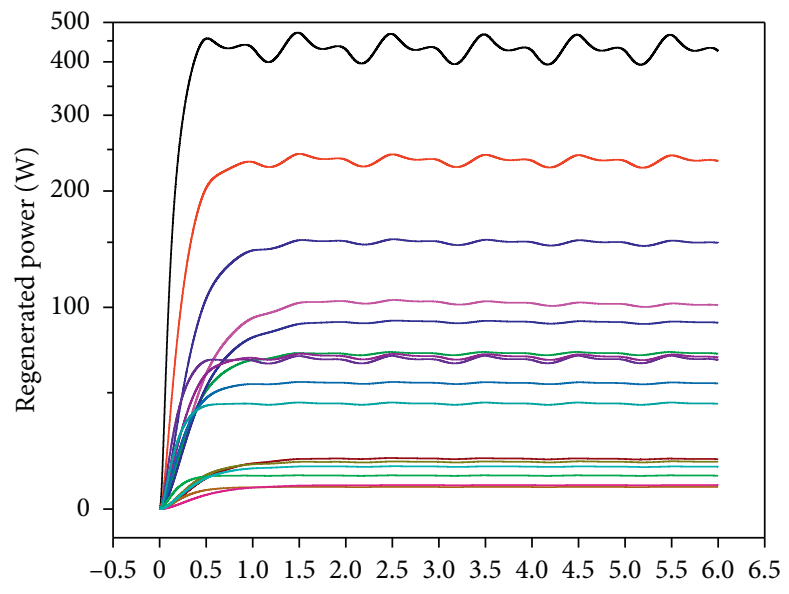

$t(\mathrm{~s})$

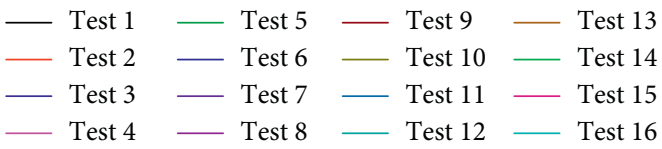

(d)

FIgURE 5: Hydraulic motor shaft speed, pressure, mechanical power, and regenerated power at different 16 tests.

key components of the test rig, including hydraulic cylinder, hydraulic accumulator, hydraulic motor, DC generator, inline check valve, and hydraulic circuits of the HERSA system, are carefully selected and equipped on the designed test bench. The HERSA test rig selected the parameters of the main components that are closest to the optimal results of the parameter optimisation. Table 11 shows the main parameter differences between model and test rig.

The input controller and road actuator are designed which are able to provide predicted input excitations including excitation displacement, excitation velocity, and frequency. Data acquisition and transducers are also applied to synchronise and measure the regenerated voltage and current across the electrical load.

The voltage and current across the electrical load were measured on the design test rig. The measured regenerated power is compared with predicted power, as shown in Figure 12. The both results of simulation and measurement are under the harmonic excitation of $1 \mathrm{~Hz}-25 \mathrm{~mm}$ with an electrical load of $20 \Omega$. It is worth to mention that the measured average regenerated power is approximately $326 \mathrm{~W}$ compared to the predicted power of up to $331 \mathrm{~W}$, and the results show a good agreement, especially for the visible 


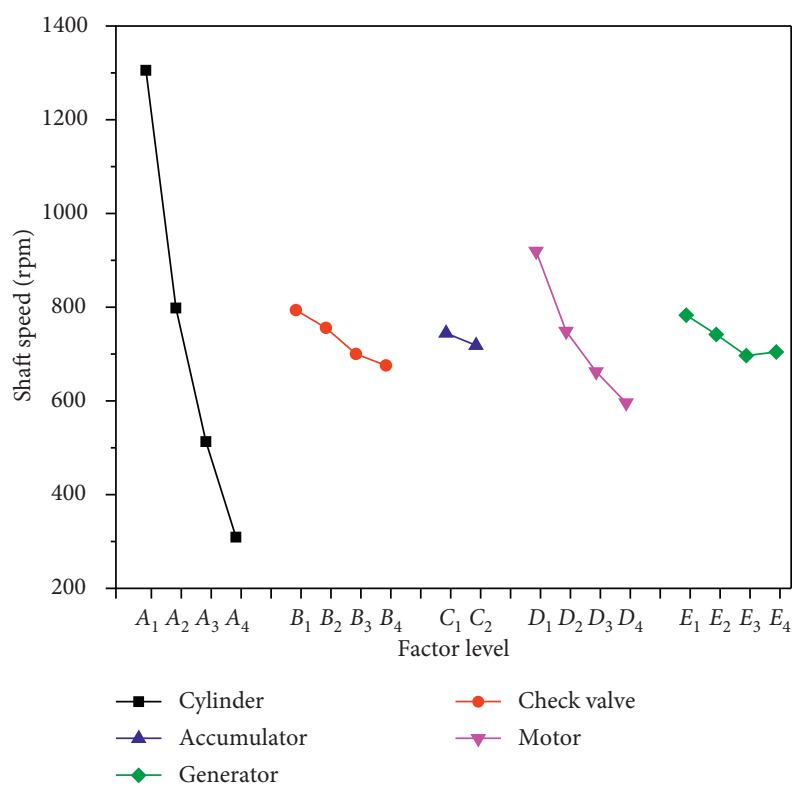

Figure 6: The index level of shaft speed at different factors.

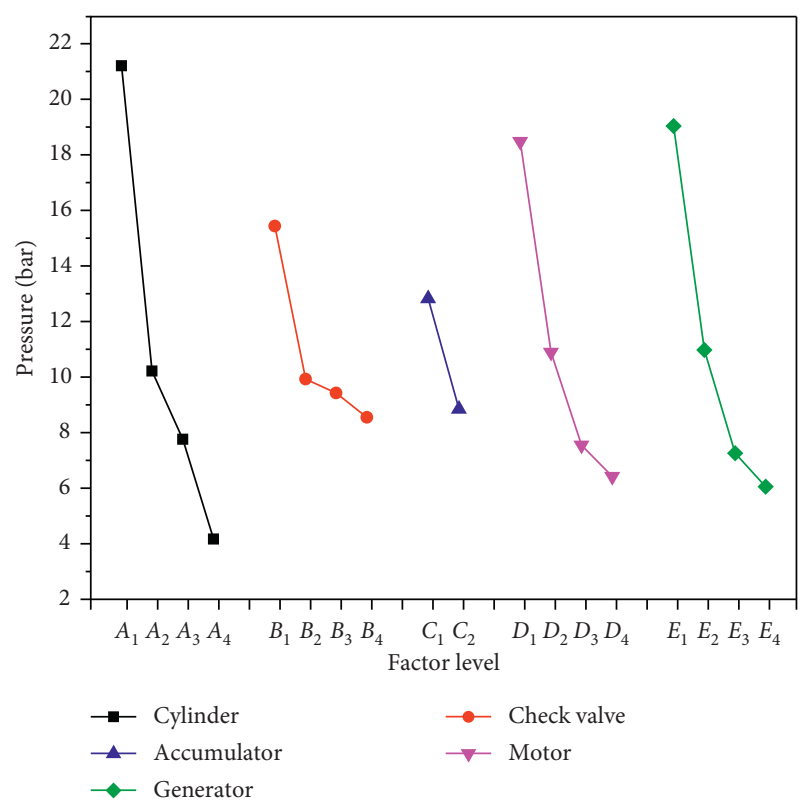

Figure 7: The index level of motor pressure at different factors.

variation trend in compression and extension strokes of cylinder.

In Figure 12, it also indicates that the peaks of power are slightly different and predicted peak is higher than that of the measured. This is because the smaller motor displacement can provide high pressure to obtain higher shaft speed with more generated power. Additionally, in real experiment, the road actuator cannot practically provide absolute stability of sinusoidal excitation due to unaccepted input error in the operating process, especially on the top and bottom of the sinusoidal waveform. It is also the underlying cause of reducing the nadir of measured value.

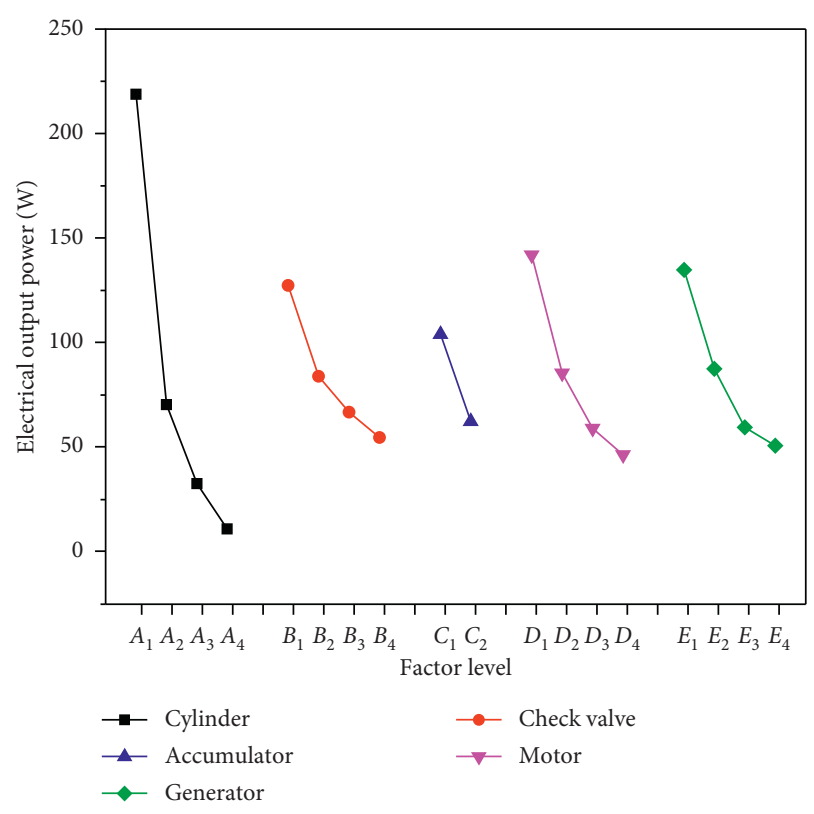

Figure 8: The index level of regenerated power at different factors.

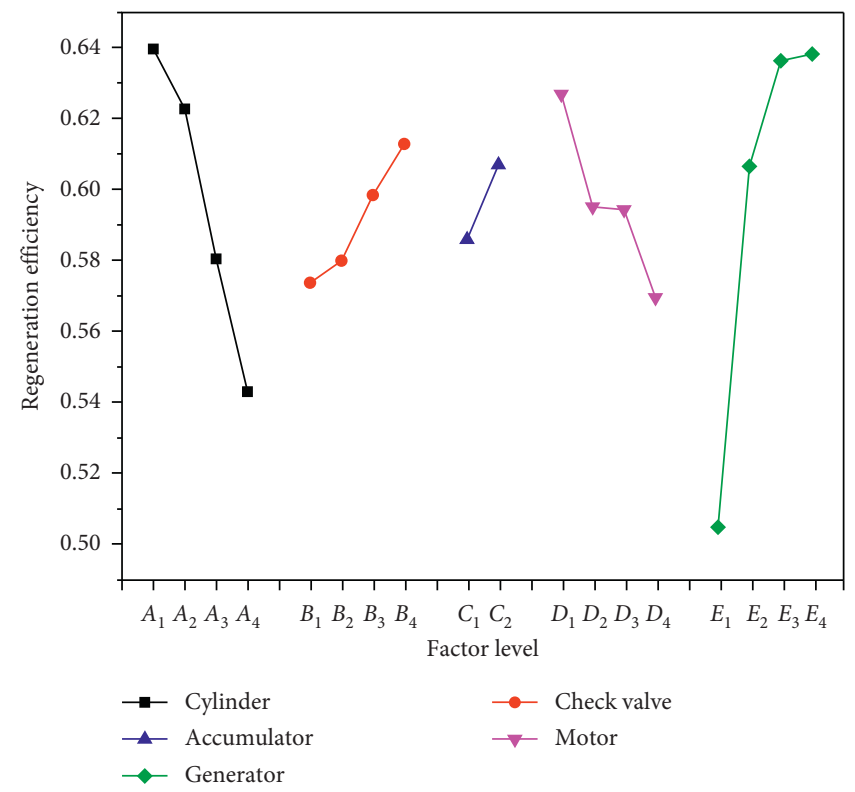

FIgure 9: The index level of regeneration efficiency at different factors.

\section{Conclusions}

In this paper, a hydraulic electric regenerative shock absorber (HERSA) is designed, modelled, and fabricated to regenerate the kinematic energy of the suspension system. To maximise the level of regenerated power and power efficiency, a parameter optimisation approach has been proposed, and the result has been validated.

A mathematical model has been proposed firstly, which consists of hydraulic cylinder, check valves, accumulator, hydraulic motor, and other components. In the dynamic model, it considers the flow variation in different chambers of cylinder (compression stroke and extension stroke), the 
TABLE 10: The rank of factors and their combination.

\begin{tabular}{lcc}
\hline Indicators & Rank of factors & Best level combinations \\
\hline Shaft speed & $A$ D E B C & $A_{1} D_{1} E_{1} B_{1} C_{1}$ \\
Hydraulic motor pressure & $A E D$ B C & $A_{1} E_{1} D_{1} B_{1} C_{1}$ \\
Regenerated power & $A D E B C$ & $A_{1} D_{1} E_{1} B_{1} C_{1}$ \\
Regeneration efficiency & $E A D B C$ & $E_{4} A_{1} D_{1} B_{4} C_{2}$ \\
\hline
\end{tabular}
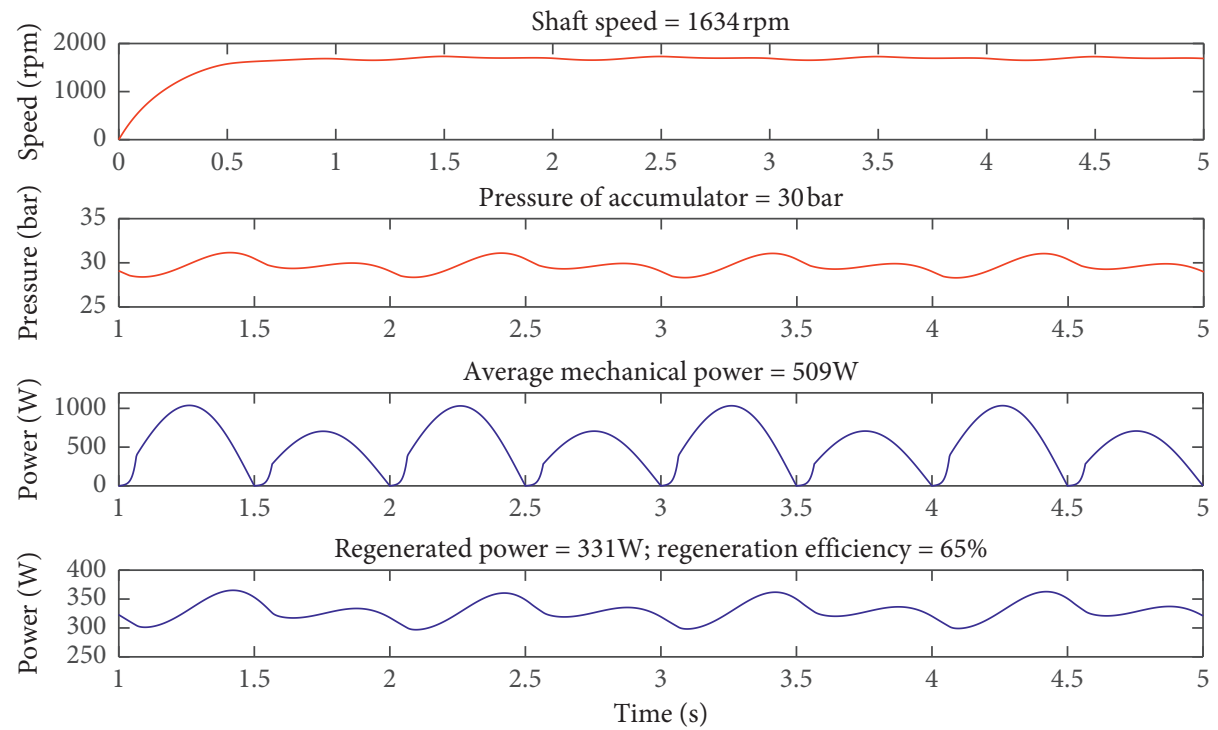

Figure 10: The results with optimal parameter combinations.

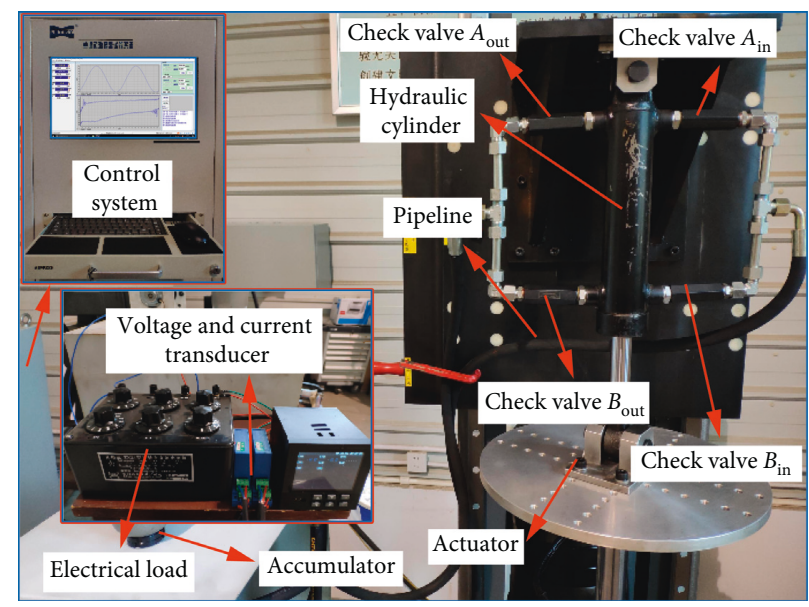

Figure 11: The HERSA test rig.

fluid bulk modulus, and the accumulator smoothing, which are beneficial to comprehensively understand the system behaviours in order to further contribute and develop the corresponding prototype.

The parameters needed to be optimised in HERSA system have been pointed out, which consist of the size of hydraulic cylinder, the size of check valves, the capacity of accumulator, the displacement of hydraulic motor, and the electrical load. The optimal values of the key components can be determined by using the orthogonal method.
In parameter optimisation, 16 tests were designed and the corresponding simulated results were obtained. According to the principle of the comprehensive equilibrium method, the optimal component combinations of the HERSA were determined and contribute to the selection of the components of the test rig. The best combinations of the key components have been determined: the size of cylinder: $50 \mathrm{~mm}$ (piston) and $28 \mathrm{~mm}$ (rod), the diameter of check valve: $6.35 \mathrm{~mm}$, the accumulator capacity: $0.63 \mathrm{~L}$, the displacement of motor: $5.77 \mathrm{cc}$, and the electrical load of 
TABLE 11: Key component differences between model and test rig.

\begin{tabular}{lcc}
\hline Parameters & Simulation & Experiment \\
\hline Hydraulic cylinder & $50-28$ & $50-30$ \\
Bore rod (mm) & & \\
Check valve (mm) & $0.35(1 / 4$ inch) & 6.35 (1/4 inch) \\
Accumulator capacity (L) & 0.635 & 0.60 \\
Hydraulic motor & 5.77 & 6.00 \\
displacement $(\mathrm{cc})$ & 20 & 20 \\
Electrical load $(\Omega)$ & & \\
\hline
\end{tabular}

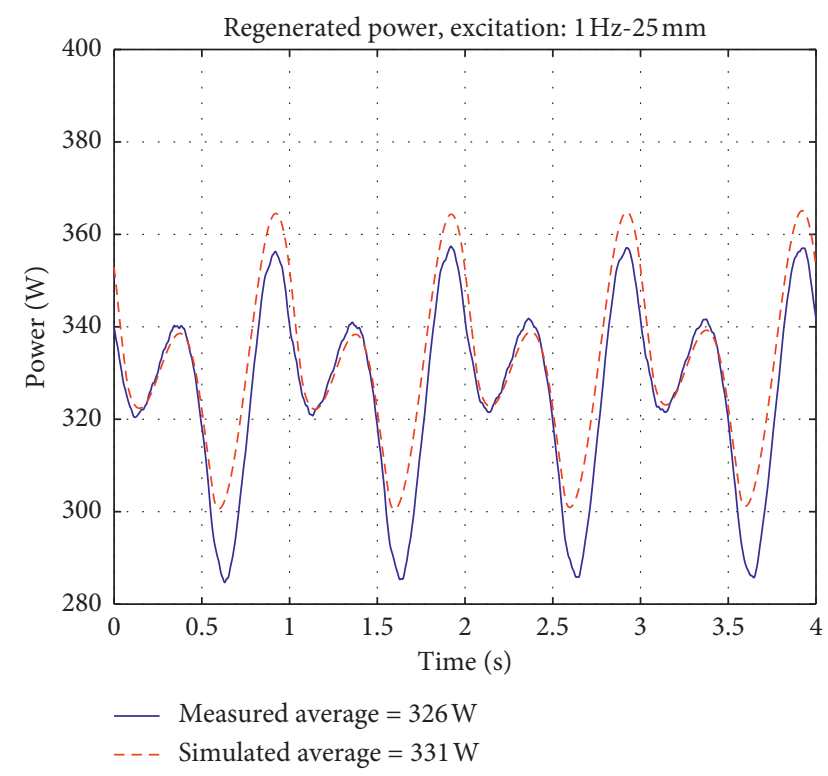

FIgURE 12: The validation of regenerated power $(1 \mathrm{~Hz}-25 \mathrm{~mm})$.

generator: $20 \Omega$, respectively. It is considered that the proposed optimisation procedure based on the orthogonal test is suitable for any general HERSA system.

It is worth mentioning that the model prediction has confirmed that the recoverable power can be achieved with the average of $331 \mathrm{~W}$ at $1 \mathrm{~Hz}-25 \mathrm{~mm}$ sinusoidal excitation with the efficiency of up to $65 \%$. In addition, the HERSA test rig is designed and fabricated in terms of the optimisation results. As a result, the experimental validation has been done and the measured results show good agreement with the simulated results, which verifies the optimisation approach's effectiveness and reliability.

It is worth noting that a HERSA system has many other objectives, such as comfort and vehicle handing stability. Particularly, feasibility study only needs to focus on the power regeneration in this paper. The studies about comfort and stability rely on the road test. Therefore, further research needs to pay more attention for the dynamic model in the future, which can satisfy irregular road profiles. And the integration of HERSA needs to be optimised for the real application.

\section{Data Availability}

The data used to support the findings of this study are included within the article.

\section{Conflicts of Interest}

The authors declare that there are no conflicts of interest regarding the publication of this paper.

\section{Acknowledgments}

This research was sponsored by the Science Foundation of National University of Defense Technology (nos. ZK17-0302 and ZK16-03-14), National Key Research and Development Program of China (no. 2017YFB1300900), Chinese National Natural Science Foundation (no. 51605483), and Sichuan Science and Technology Program (2019JDRC0081).

\section{References}

[1] R. Wang, Z. Chen, H. Xu, K. Schmidt, F. Gu, and A. D. Ball, "Modelling and validation of a regenerative shock absorber system," in Proceedings of the 2014 20th International Conference on Automation and Computing, IEEE, Cranfield, UK, September 2014.

[2] L. Segel and X. Lu, "Vehicular resistance to motion as influenced by road roughness and highway alignment," Australian Road Research, vol. 12, no. 4, pp. 211-222, 1982.

[3] A. Browne and J. Hamburg, "On road measurement of the energy dissipated in automotive shock absorbers," in Proceedings of the Symposium on Simulation and Control of Ground Vehicles and Transportation Systems, vol. 80, no. 2, Anaheim, CA, USA, 1986.

[4] P. Hsu, "Power recovery property of electrical active suspension systems," in Proceedings of the 31st Intersociety Energy Conversion Engineering Conference (IECEC 96), vol. 3, IEEE, Washington, DC, USA, August 1996.

[5] H. Zhang, X. X. Guo, and Z. G. Fang, "Potential energy harvesting analysis and test on energy-regenerative suspension system," Journal of Vibration, Measurement \& Diagnosis, vol. 35, no. 2, pp. 225-230, 2015.

[6] Y. Okada and H. Harada, "Regenerative control of active vibration damper and suspension systems," in Proceedings of 35th IEEE Conference on Decision and Control, vol. 4, IEEE, Kobe, Japan, December 1996.

[7] Y. Okada and K. Ozawa, "Energy regenerative and active control of electro-dynamic vibration damper," in Proceedings of the IUTAM Symposium on Vibration Control of Nonlinear Mechanisms and Structures, Springer, Munich, Germany, July 2005.

[8] K. Nakano, Y. Suda, S. Nakadai, and Y. Koike, "Anti-rolling system for ships with self-powered active control," JSME International Journal Series C, vol. 44, no. 3, pp. 587-593, 2001.

[9] K. Nakano, Y. Suda, and S. Nakadai, "Self-powered active vibration control using a single electric actuator," Journal of Sound and Vibration, vol. 260, no. 2, pp. 213-235, 2003.

[10] W. D. Jones, "Easy ride Bose Corp. uses speaker technology to give cars adaptive suspension," IEEE Spectrum, vol. 42, no. 1, p. 68, 2005.

[11] Y. Zhang, K. Huang, F. Yu, Y. Gu, and D. Li, "Experimental verification of energy-regenerative feasibility for an automotive electrical suspension system," in Proceedings of the 2007 IEEE International Conference on Vehicular Electronics and Safety, IEEE, Beijing, China, December 2007. 
[12] Z. Li, L. Zuo, J. Kuang, and G. Luhrs, "Energy-harvesting shock absorber with a mechanical motion rectifier," Smart Materials and Structures, vol. 22, no. 2, article 025008, 2013.

[13] Z. Fang, X. Guo, L. Xu, and H. Zhang, "Experimental study of damping and energy regeneration characteristics of a hydraulic electromagnetic shock absorber," Advances in Mechanical Engineering, vol. 5, article 943528, 2013.

[14] Z. G. Fang, X. X. Guo, L. Xu, and J. Zhang, "Researching on valve system of hydraulic electromagnetic energyregenerative shock absorber," Applied Mechanics and Materials, vol. 157-158, pp. 911-914, 2012.

[15] Z. Fang, X. Guo, L. Xu, and H. Zhang, "An optimal algorithm for energy recovery of hydraulic electromagnetic energyregenerative shock absorber," Applied Mathematics \& Information Sciences, vol. 7, no. 6, pp. 2207-2214, 2013.

[16] Z. Fang, X. Guo, L. Zuo et al., "Theory and experiment of damping characteristics of hydraulic electromagnetic energyregenerative shock absorber," Journal of Jilin University (Engineering and Technology Edition), vol. 44, no. 4, pp. 939-945, 2014.

[17] C. Li, R. Zhu, M. Liang, and S. Yang, "Integration of shock absorption and energy harvesting using a hydraulic rectifier," Journal of Sound and Vibration, vol. 333, no. 17, pp. 39043916, 2014.

[18] P. Zheng, R. Wang, and J. Gao, "A comprehensive review on regenerative shock absorber systems," Journal of Vibration Engineering \& Technologies, pp. 1-22, 2019.

[19] L. Xu and X. Guo, "Hydraulic transmission electromagnetic energy-regenerative active suspension and its working principle," in Proceedings of the 2010 2nd International Workshop on Intelligent Systems and Applications, IEEE, France, October 2010.

[20] R. Wang, F. Gu, R. Cattley, and A. Ball, "Modelling, testing and analysis of a regenerative hydraulic shock absorber system," Energies, vol. 9, no. 5, p. 386, 2016.

[21] K. Ahmad and M. Alam, "Design and simulated analysis of regenerative suspension system with hydraulic cylinder, motor and dynamo," in Proceedings of the SAE Technical Paper Series (No. 2017-01-1284), USA, March 2017.

[22] H. Zhang, G. Li, Y. Wang, Y. Gu, X. Wang, and X. Guo, "Simulation analysis on hydraulic-electrical energy regenerative semi-active suspension control characteristic and energy recovery validation test," Transactions of the Chinese Society of Agricultural Engineering, vol. 33, no. 16, pp. 64-71, 2017.

[23] X. Guo, H. Liu, B. Wang, and Z. Xu, "Road surface roughness measurement and its reconstruction," Vehicle \& Power Technology, vol. 4, pp. 14-18, 2010.

[24] B. Christoph, Hydraulische achsantriebe im digitalen regelkreis, Ph.D. thesis, RWTH Aachen University, Aachen, Germany, 1995.

[25] L. I. Wenjing and A. N. Gongchang, Application of Kirchhoff's Voltage Law in Circuit Analysis, University of Electronic Science and Technology, Chengdu, China, 2013.

[26] ISO 3320-2013, Fluid Power Systems and Components-Cylinder Bores and Piston Rod Diameters and Area Ratios. Metric Series, International Organization for Standardization (ISO), Geneva, Switzerland, 2013.

[27] Z. A. Xu, T. B. Wang, and C. Y. Li, Brief Introduction to the Orthogonal Test Design, China Building Materials Science \& Technology, Zhaoqing, China, 2011.

[28] R. H. Dong, B. H. Xiao, and Y. S. Fang, "The theoretical analysis of orthogonal test designs," Journal of Anhui Institute of Architecture, vol. 6, p. 29, 2004. 


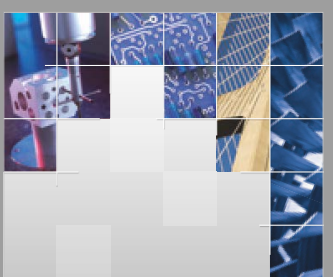

\section{Enfincering}
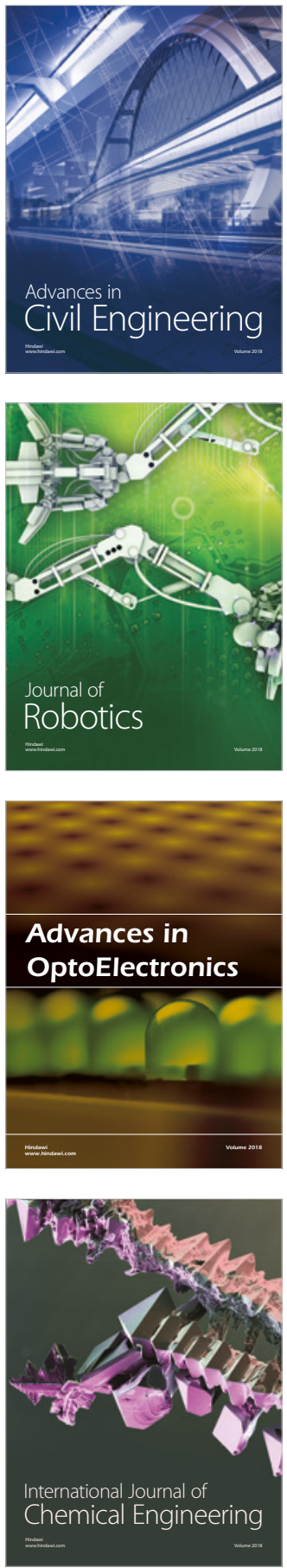

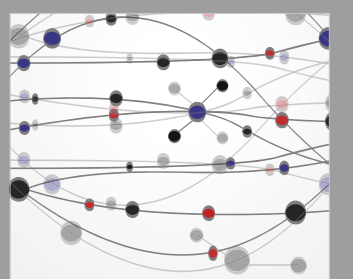

\section{Rotating \\ Machinery}

The Scientific World Journal

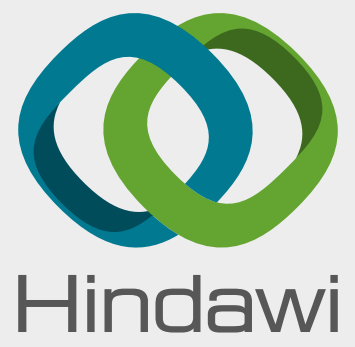

Submit your manuscripts at

www.hindawi.com
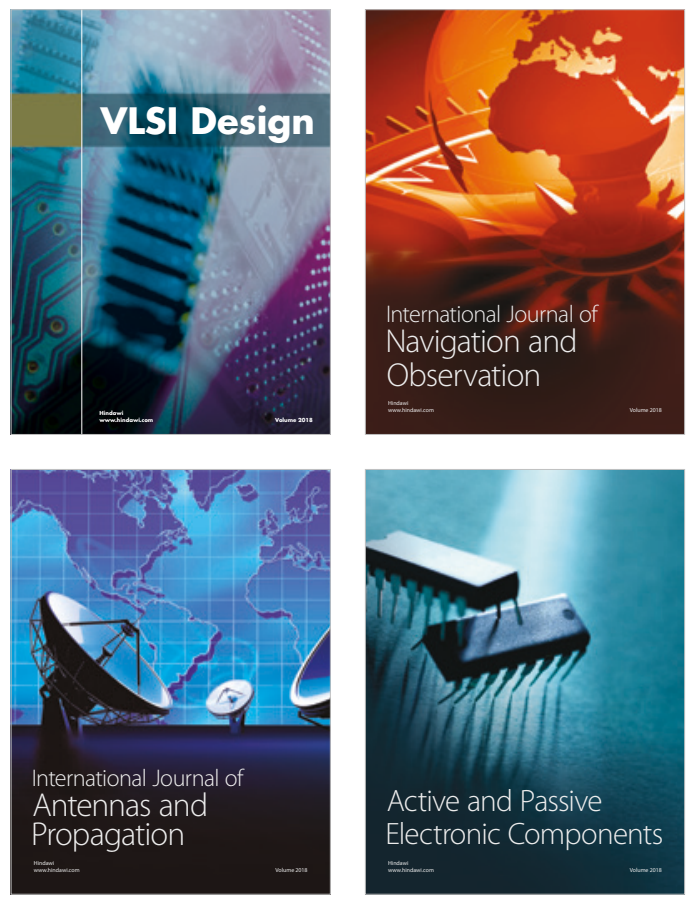
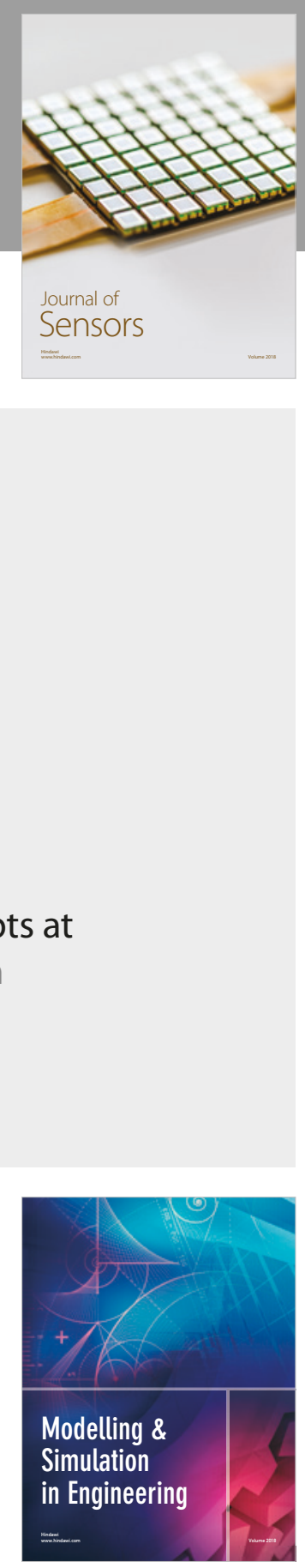

\section{Advances \\ Multimedia}
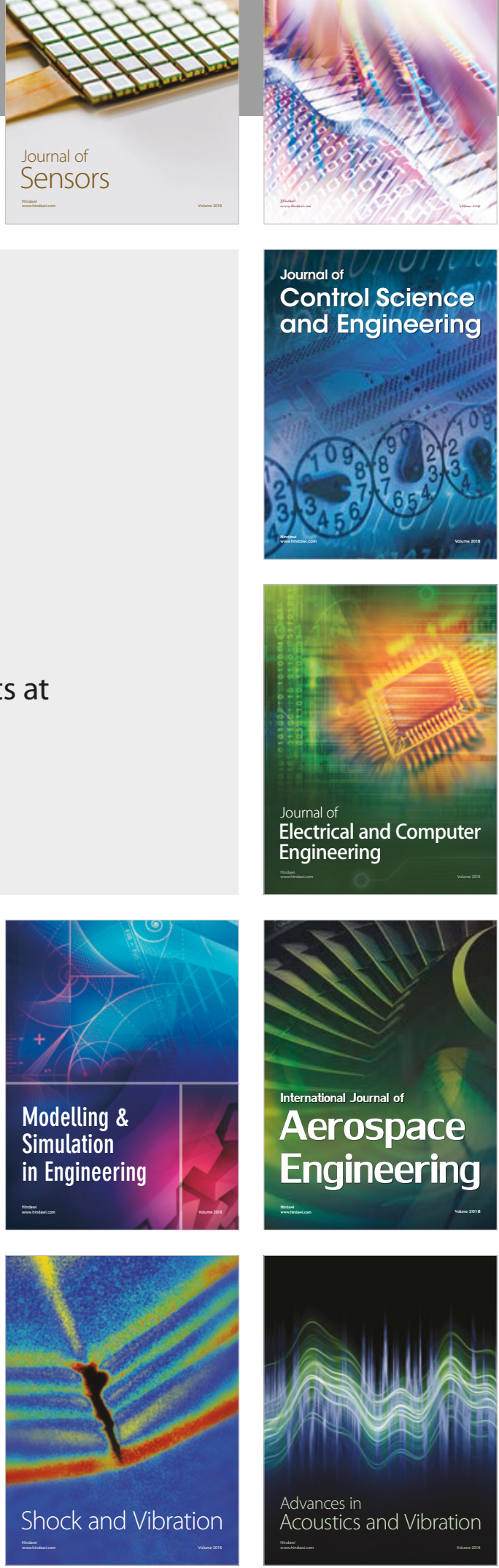